\title{
Facial flushing after thermocoagulation of the Gasserian ganglion
}

\author{
PD DRUMMOND, A GONSKI, JW LANCE \\ From the Departments of Neurology and Neurosurgery, The Prince Henry Hospital, Sydney, Australia
}

SUMMARY The development of a facial flush during thermocoagulation of the Gasserian ganglion was monitored in 16 patients with pulse recording techniques and in a further 17 patients with thermography. There was a close association between the development of the facial flush in the distribution of one or more divisions of the trigeminal nerve and the subsequent demonstration of postoperative analgesia. In regions where significant changes took place, vascular pulsations increased $25-233 \%$ (mean $96 \%$ ) and facial temperature rose $0 \cdot 5-2 \cdot 0^{\circ} \mathrm{C}$. The response persisted for up to an hour postoperatively, and was not diminished in patients with pre-operative analgesia from a previous procedure. Possible mechanisms for the facial flush, including stimulation of an active vasodilator system, the antidromic release of vasoactive substances from trigeminal nerve terminals and the release of tonic vasoconstriction are discussed. A practical application of the pulse recording technique used in the present investigation would be to monitor the distribution of vasodilatation at operation to avoid unwanted first division sensory loss.

Flushing on one side of the face may follow an attack of trigeminal neuralgia ${ }^{1}$ and has been observed after injection of alcohol into the ipsilateral trigeminal (Gasserian) ganglion. ${ }^{2}$ Rowbotham ${ }^{2}$ commented that facial temperature and skin colour did not alter after tractotomy, root section or intracranial neurectomy, and attributed the rise in skin temperature after alcohol injection of the ganglion to involvement of sympathetic fibres either in the ganglion or adjacent to it. $\mathrm{Oka}^{3}$ reported that temperature increased on one or both sides of the face following injection of alcohol into the Gasserian ganglion, the response reaching its peak 10-30 minutes after injection and persisting for $40-120$ minutes.

Similar observations have been made after thermocoagulation of the Gasserian ganglion. Sweet and Wepsic ${ }^{4}$ commented that flushing was limited to the skin distribution of the appropriate division of the trigeminal nerve. Onofrio ${ }^{5}$ confirmed this and remarked that the blush did not appear if the sensory root, ganglion or sensory division had previously been damaged sufficiently to cause dense anaesthesia. He considered that the phenomenon was more likely to be caused by stimulation of a

Address for reprint requests: Professor JW Lance, The Prince Henry Hospital, Little Bay, 2036, New South Wales, Australia.

Received 2 November 1982. Accepted 20 November 1982 vasodilator system than destruction of sympathetic fibres.

The aim of the present investigation was to provide an objective assessment of these clinical observations, to determine the localization and time course of facial flushing after thermocoagulation and to ascertain, if possible, whether it was caused by excitation of vasodilator fibres, destruction of a tonic vasoconstrictor influence, or both.

\section{Patients and methods}

\section{Patients}

Observations were made on 33 patients, 17 male and 16 female, aged 33-90 years (mean 63 years) undergoing thermocoagulation of the Gasserian ganglion. The indications for the procedure were trigeminal neuralgia (27), atypical facial pain (3), carcinoma invading the trigeminal nerve (2) and cluster headache (1). Two patients who experienced recurrence of pain postoperatively were studied a second time when the procedure was repeated. Facial sensation was examined clinically before and after operation.

\section{Procedure}

The operative technique was similar to that described by Sweet and Wepsic ${ }^{4}$ and Onofrio. ${ }^{5} \mathrm{~A}$ thermistor needle was inserted through the foramen ovale under local anaesthesia, the position of the tip being monitored fluoroscopically and confirmed by radiographs. While the patient was conscious, the Gasserian ganglion was stimulated electri- 
cally $(10 \mathrm{v}$ peak, $0 \cdot 5-1 \cdot 0 \mathrm{~ms}$ pulses, $5 \mathrm{~Hz}$ for $10-30 \mathrm{~s})$ to check that paraesthesiae were referred to the appropriate division or divisions. The patient was then fully anaesthetised for a brief period during thermocoagulation $\left(70^{\circ} \mathrm{C}\right.$ for 1-2 minutes). In some instances a second lesion was made after repositioning the needle slightly.

\section{Methods}

In 16 patients, infrared photocells (Narco Bio-Systems) were fastened with adhesive washers to the forehead, cheek, or chin of the symptomatic side and one area (usually the cheek) of the opposite side. Providing that the photocells are not placed over a superficial artery they measure changes in capillary perfusion, ${ }^{6}$ a technique known as photoplethysmography. Recordings were made before-and during preliminary electrical stimulation (six patients) and before, during and after thermocoagulation (16 patients). Measurements were taken 15, 30 and 60 seconds after the tip of the needle reached $70^{\circ} \mathrm{C}$, from which the mean amplitude was calculated and expressed as a percentage of pre-coagulation amplitude for statistical purposes. Recordings were continued for 10 minutes after the procedure in seven patients and for up to 60 minutes in three patients.

Heat loss from the face was measured in 17 patients before, during and after the procedure, using an AGA thermovision camera sensitive to infrared radiation. To obtain thermograms during the operative procedure a mirror, angled at $45^{\circ}$, was positioned above the face of the supine patient $23 \mathrm{~cm}$ in front of the thermovision camera. The thermogram was photographed on Polaroid film with each isotherm, separated by $0 \cdot 5^{\circ} \mathrm{C}$, being photographed through a different coloured filter. The thermogram was thus a photograph portraying in colour each facial isotherm (Plate 1), the isotherms being calibrated by reference to a disc maintained at $34^{\circ} \mathrm{C}$ placed next to the patient's head. Observations were continued for up to 30 minutes after the procedure in eight patients and another measurement was taken the following day in seven patients.

\section{Results}

\section{PHOTOPLETHYSMOGRAPHY}

Vascular pulsations did not change significantly from baseline in any of the six patients during preliminary electrical stimulation. On the nonsymptomatic side of the face, pulsations varied in amplitude during thermocoagulation from $-47 \%$ to $+25 \%$ of the control value (mean $-7 \%$, SD $15 \%$ ), presumably as a non-specific reaction to anaesthesia and operative intervention. For assessment of dilatation on the operated side, any increase in vascular pulsation in excess of two standard deviations of the mean on the unoperated side, that is in excess of $23 \%$, was deemed to be significant.

In the cutaneous distribution of the trigeminal nerve where significant changes took place, pulsations increased 25-233\% (mean 96\%, SD 62\%) (fig 1). The response became apparent as the tip of the needle reached $70^{\circ} \mathrm{C}$ and was of similar mag-

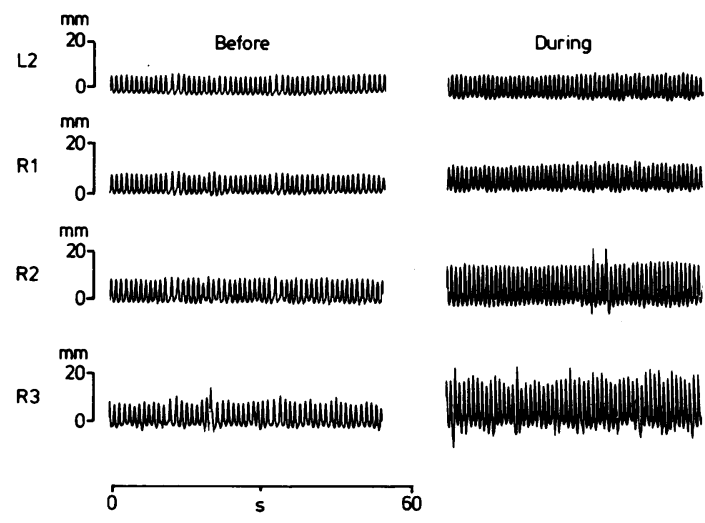

Fig 1 Increase in amplitude of pulsation in the distribution of the second and third divisions of the right trigeminal nerve during thermocoagulation. Analgesia was detected postoperatively in the two divisions showing increased vascular pulsations during thermocoagulation.

nitude in each of the three divisions, mean increases being $92 \%$ for the first division, $111 \%$ for the second division and $85 \%$ for the third division. Pulsations remained increased for up to an hour after thermocoagulation (fig 2) but the change was statistically significant for only the first 10 minutes because of the relatively small numbers studied.

Two lesions were made during the one procedure in nine patients. Vascular pulsations increased by only $10 \%$ after the second lesion, an insignificant change.

The increase in vascular pulsation in the cutaneous distribution of each division correlated positively with the demonstration of postoperative analgesia in that division (table 1, fig 3 ). In a further five patients with pre-operative analgesia from a previous procedure, augmentation of vascular pulsation was observed in 8 of the 12 divisions studied (fig 3).

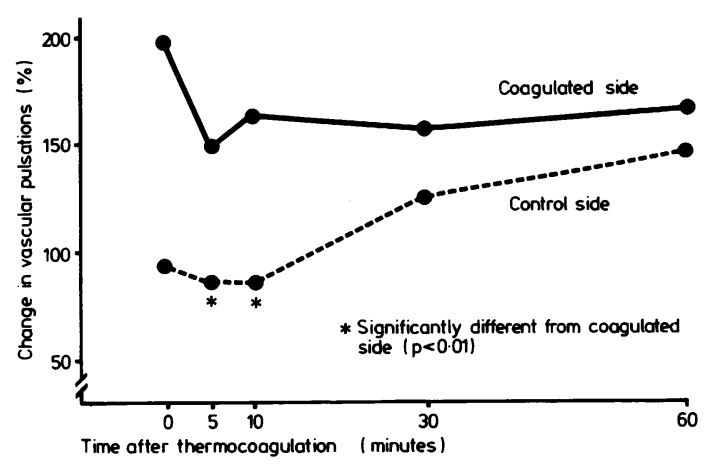

Fig 2 Time course of increased vascular pulsation following thermocoagulation. 


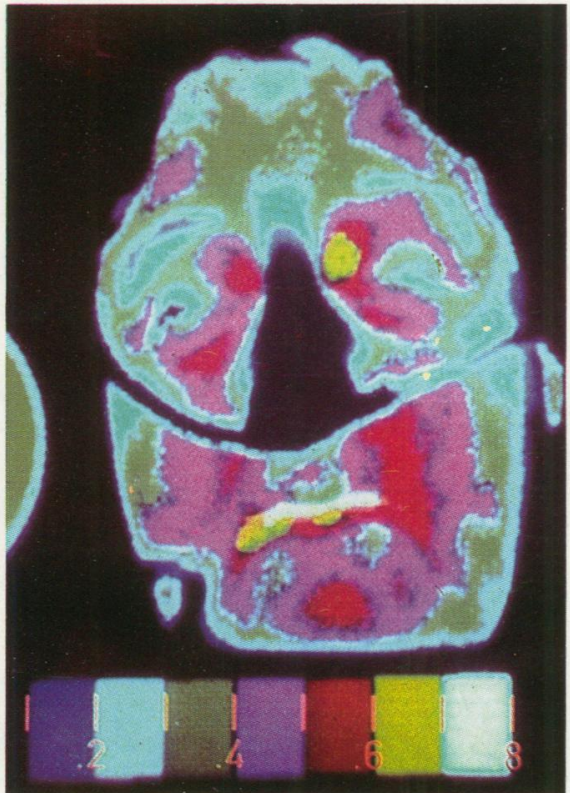

$a$

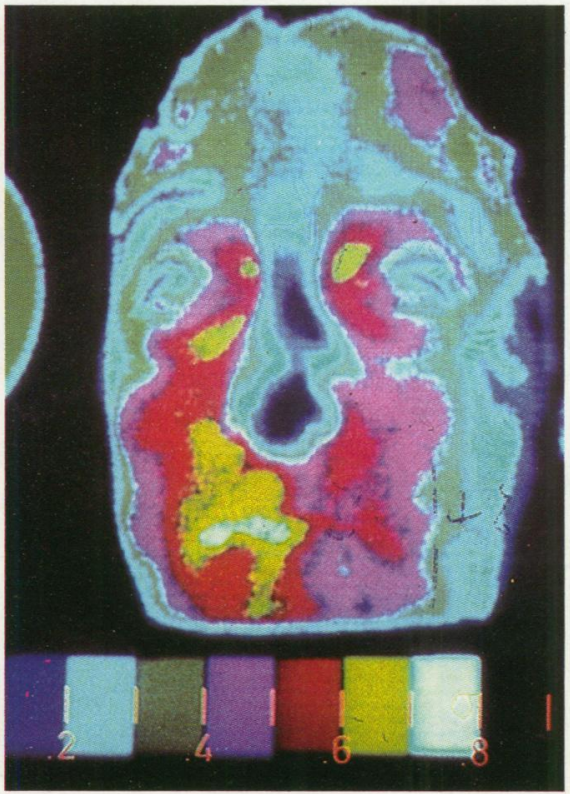

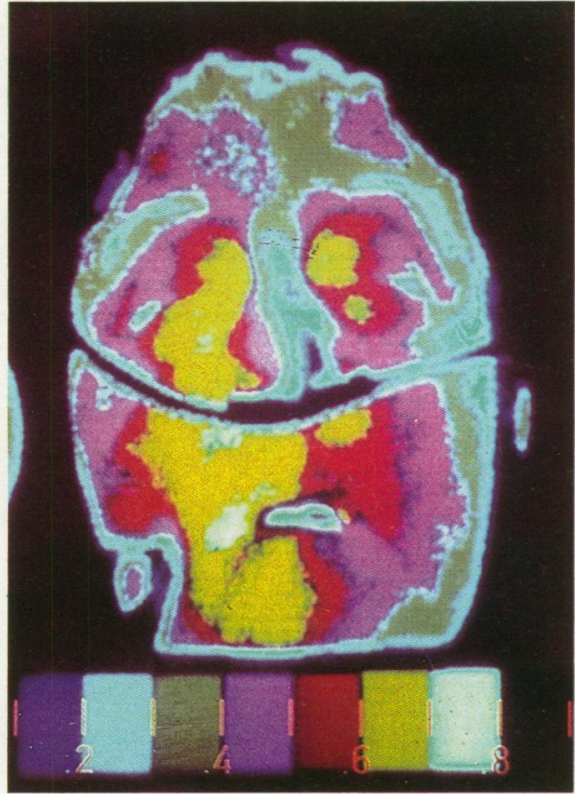

$b$

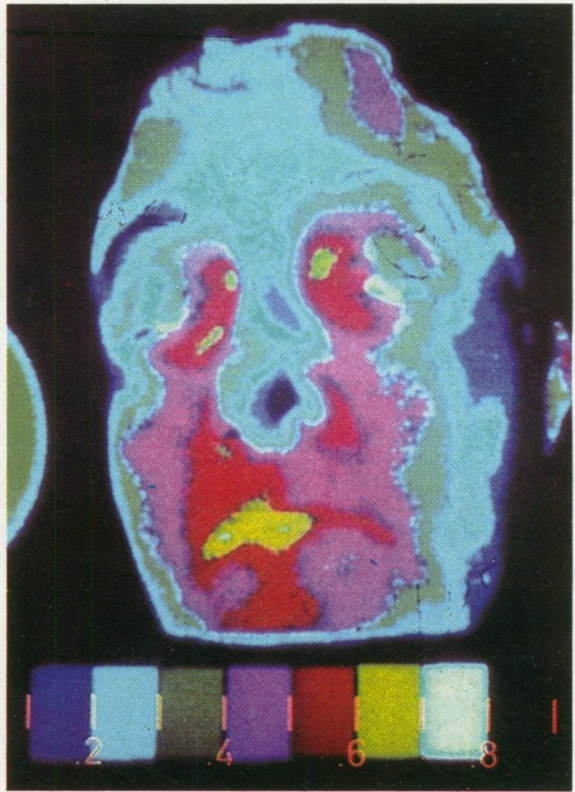

$d$

Plate Temperature changes during thermocoagulation. Thermograms are calibrated by reference to the green disc maintained at $34^{\circ} \mathrm{C}$. Each colour represents an isotherm of $0.5^{\circ} \mathrm{C}$ ranging from $33.0-33.5^{\circ} \mathrm{C}$ (blue) to $36 \cdot 0-36.5^{\circ} \mathrm{C}$ (white). Thermograms of a patient (a) before and (b) during thermocoagulation, demonstrating an increase of $0.5-1.0^{\circ} \mathrm{C}$ on the operated side during thermocoagulation, (c) Thermograms $15 \mathrm{~min}$ and (d) 30 min after the procedure, showing the time course of the facial fush. 
Table 1 Association between increased vascular pulsation in the distribution of a given division of the trigeminal nerve with the subsequent finding of analgesia in that division

\begin{tabular}{llcll}
\hline Analgesia & \multicolumn{2}{l}{ Increased vascular pulsation } & Chi-squared \\
\cline { 2 - 4 } & Yes & No & Total & \\
\hline Yes & 13 & 5 & 18 & $8 \cdot 13$ \\
No & 3 & 11 & 14 & $(\mathrm{p}<0 \cdot 01)$ \\
Total & 16 & 16 & 32 & \\
\hline
\end{tabular}
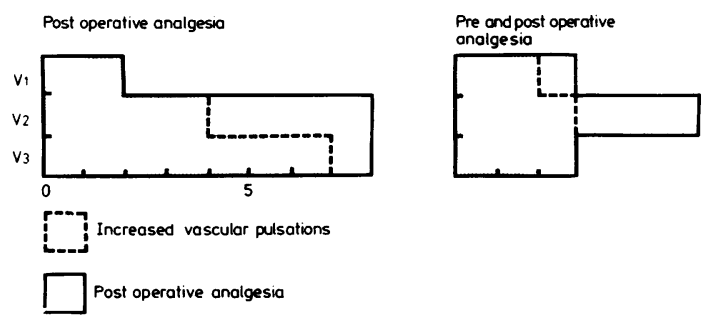

Fig 3 Increased vascular pulsation in regions where analgesia was detected postoperatively.

THERMOGRAPHY

In the 17 patients studied, heat loss from the skin supplied by each of the three divisions of the trigeminal nerve on the symptomatic side was compared with the non-symptomatic side before, during and after the operative procedure. On the nonsymptomatic side, skin temperature increased by at least $0.5^{\circ} \mathrm{C}$ in 25 of 51 divisions and decreased by the same extent in only two divisions. These changes were attributed to a generalised autonomic reaction resulting from anaesthesia and operation. Before thermocoagulation, skin temperature on the symptomatic side was greater than on the nonsymptomatic side by at least $0.5^{\circ} \mathrm{C}$ in 21 of the 51 divisions and was cooler in only two divisions. This asymmetry presumably was caused by injection of local anaesthetic, insertion of the thermistor needle or other operative procedures.

For these reasons, increases in skin temperature on the operated side during thermocoagulation were regarded as significant only when they exceeded by $0.5^{\circ} \mathrm{C}$ the ipsilateral pre-operative temperature and the contralateral postoperative temperature in the appropriate division. According to these criteria, a flush developed on the operated side in 30 of 51 divisions (Plate 1), increases being $0 \cdot 5-1 \cdot 0^{\circ} \mathrm{C}$ in the first and second division and up to $2.0^{\circ} \mathrm{C}$ in the third division (table 2). There was a significant association between the appearance of the flush and the development of postoperative analgesia (fig 4) although the flush sometimes spread to adjacent regions that were not rendered analgesic (table 3 ). The
Table 2 Number of patients showing increases in skin temperature in the distribution of each of the three divisions of the trigeminal nerve

\begin{tabular}{llll}
\hline Division & \multicolumn{3}{l}{ Temperature Increase } \\
\cline { 2 - 4 } & $0 \cdot 5^{\circ} \mathrm{C}$ & $1 \cdot 0^{\circ} \mathrm{C}$ & $1 \cdot 5-2 \cdot 0^{\circ} \mathrm{C}$ \\
\hline First & 5 & 2 & 0 \\
Second & 6 & 7 & 0 \\
Third & 3 & 5 & 2 \\
\hline
\end{tabular}

Table 3 Association between facial fush (detected thermographically) in the distribution of a given division of the trigeminal nerve with the subsequent finding of analgesia in that division

\begin{tabular}{llrll}
\hline Analgesia & \multicolumn{2}{l}{ Flush } & \multicolumn{2}{c}{ Chi-squared } \\
\cline { 2 - 4 } & Yes & No & Total & \\
\hline Yes & 15 & 4 & 19 & $7 \cdot 20$ \\
No & 11 & 17 & 28 & $(\mathrm{p}<0 \cdot 01)$ \\
Total & 26 & 21 & 47 & \\
\hline
\end{tabular}

flush also became apparent in two patients with analgesia from previous thermocoagulations and in one patient with analgesia of the second and third divisions as the result of a partial section of the trigeminal root central to the ganglion 10 years previously (fig 4). Analgesia developed in four regions without facial flushing (table 3 ). The face was $0.5-$ $1.0^{\circ} \mathrm{C}$ hotter than the contralateral side preoperatively in three of these regions, which may have masked facial flushing during thermocoagulation.

In nine patients who showed a flush during thermocoagulation, a second lesion was made after repositioning the thermistor needle. The flush was accentuated in three patients but did not alter in the other six patients.

Flushing persisted in 11 of 17 divisions in patients examined 10-15 minutes postoperatively and in five of 11 regions in those studied 30 minutes after the procedure. There was no evidence of flushing in seven patients examined the following day.

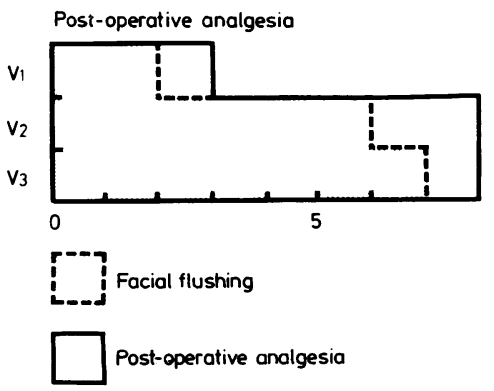

Pre and post operative analgesia

Fig 4 Facial fushing in regions where analgesia was detected postoperatively. 


\section{Discussion}

The present findings confirm previous clinical observations of unilateral facial flushing in a divisional distribution during and after thermocoagulation of the Gasserian ganglion. In most instances the flush was limited to the distribution of the division or divisions in which analgesia was detected postoperatively but it was occasionally observed in an adjacent division. Vasodilatation was usually maximal within 15-30 seconds of the start of the coagulation and a second lesion made during the same procedure had little or no additional effect.

Possible mechanisms for the flushing phenomenon include the stimulation of a vasodilator pathway, ${ }^{5}$ the antidromic release of substance $P$ or other vasoactive substances from terminals of the trigeminal nerve ${ }^{7}$ or the destruction of a tonic vasoconstrictor system. There is physiological evidence for both constrictor and dilator mechanisms in man. By studying skin temperature after blocking the supraorbital, greater auricular, external nasal, infraorbital and mental nerves, Fox, Goldsmith and Kidd ${ }^{8}$ concluded that the cutaneous circulation of the ear, lip and nose was subject to a tonic vasoconstrictor influence whereas active dilatation in response to heat was more important in controlling skin temperature of the forehead and chin.

Gonzalez, Onofrio and Kerr' reported that stimulation of each division of the trigeminal nerve in the cat $(9-12 \mathrm{v}, 1 \mathrm{~ms}$ pulses, $100 \mathrm{~Hz}$ for $2-3 \mathrm{~min}$ ) caused an increase in skin temperature in the appropriate cutaneous distribution of up to $3^{\circ} \mathrm{C}$ for the third division, $2.2^{\circ} \mathrm{C}$ for the second division and $1.0^{\circ} \mathrm{C}$ for the first. The response began after a latency of 5-8 s and lasted for 6-8 $\mathrm{min}$. The vascular response was not altered by acute transection of the trigeminal root, was slightly depressed by chronic transection of the root, and was abolished by a combined lesion of trigeminal root and facial nerve. Stimulation of the facial nerve or its greater superficial petrosal branch evoked temperature increases which were abolished in the distribution of a particular division of the trigeminal nerve by transection of that division. It was concluded that the flushing response depended to a minor degree on fibres emerging from the brainstem in the trigeminal root but mainly upon greater superficial petrosal fibres which joined the Gasserian ganglion and were distributed with each of the three divisions of the trigeminal nerve. This question must remain open because meticulous dissection of the heads of five cats by Dr N Bogduk in our laboratory could not demonstrate any anatomical connection between the greater superficial petrosal nerve and the Gasserian ganglion.

On the other hand, there is anatomical evidence in the cat that the internal carotid nerve supplies sympathetic fibres to the third, ${ }^{10}$ second ${ }^{10}$ and first ${ }^{11}$ divisions of the trigeminal nerve, joining the Gasserian ganglion on its under surface and being distributed with each trigeminal branch. Matthews and Robinson ${ }^{10}$ showed that sectioning the cervical sympathetic trunk in two cats led to a sustained rise in lip temperature of $1.0^{\circ} \mathrm{C}$ and $1.7^{\circ} \mathrm{C}$ respectively, a release phenomenon which has also been noted in man after sympathectomy. ${ }^{12}$ Conversely, stimulation of the distal end of the cut sympathetic trunk in five cats caused a fall in lip temperature of up to $3.0^{\circ} \mathrm{C}$. When the constrictor response was blocked by intravenous phentolamine in two animals, stimulation of the inferior alveolar nerve caused a temperature increase of $2.3^{\circ} \mathrm{C}$ and $2.5^{\circ} \mathrm{C}$ respectively. There is thus a tonic vasoconstrictor system present in peripheral branches of the cat trigeminal nerve, originating from the cervical sympathetic system, mediated at least in part by fibres from the internal carotid nerve which traverse the Gasserian ganglion. There is also an active vasodilator system present in branches of the trigeminal nerve which is unmasked when sympathetic activity is blocked by phentolamine. ${ }^{10}$ The experiments of Gonzalez, Onofrio and Kerr' ${ }^{9}$ suggested that this vasodilator system originates in the greater superficial petrosal branch of the facial nerve and can be influenced by stimulation of the Gasserian ganglion although we have not been able to demonstrate an anatomical connection between the greater superficial petrosal and trigeminal nerves in the cat. ${ }^{11}$ The suggestion of Moskowitz et $\mathrm{al}^{7}$ that stimulation of the trigeminal nerve may release a vasodilator such as substance $P$ from afferent terminals in the skin must therefore be seriously entertained. There is evidence that stimulation of the trigeminal ganglion releases substance $P$ in the eye and tooth pulp in the cat ${ }^{13}{ }^{14}$ and increases pulp blood flow. ${ }^{14}$ Capillary transudation is increased in the trigeminal distribution by stimulation of the rat trigeminal ganglion. ${ }^{\text {is }}$

What is the most likely mechanism for the sustained flush in man? It is unlikely to be the result of a centrally-mediated reflex since we observed the flushing response in a patient with previous section of that part of the trigeminal root containing fibres from divisions in which the flush appeared. It could not be the release of tonic sympathetic vasoconstriction because the only demonstrable connection between the sympathetic nervous system and the trigeminal nerve in man is a branch of the internal carotid nerve which runs briefly with the sixth cranial nerve before being distributed solely to the first trigeminal division. ${ }^{16} \mathrm{It}$ is unlikely that it depends on the antidromic release of vasodilator substances from trigeminal nerve terminals responsible for pain 
sensibility ${ }^{7}$ since a flush of equal intensity was observed after re-operation on patients with analgesia from previous surgery in whom a substantial proportion of pain fibres must have degenerated. Facial flushing may have resulted from spread of stimulation to the greater superficial petrosal nerve which lies in close proximity to the Gasserian ganglion in man, ${ }^{17}$ although it is difficult to see how the flush could be limited to the distribution of only one or two divisions of the trigeminal nerve if this were the case. The possibility remains that the flush may depend on antidromic release of chemical transmitters such as substance $\mathbf{P}$ from large diameter fibres or pain fibres which survive thermocoagulation. No inference can be drawn from the failure of preliminary electrical stimulation to alter vascular pulsations in our patients since only low-frequency pulses $(5 / \mathrm{sec})$ were used. Further elucidation of the mechanism will depend on animal experimentation.

A practical application of the techniques employed in this study would be to monitor the distribution of vasodilatation at operation, since surgeons usually wish to avoid implicating the first division. Photoplethysmography would be preferable to thermography for this purpose because it is simpler, cheaper, and detects the onset of vasodilatation before a visible flush appears.

This study received generous support from the JA Perini Family Trust. The illustrations were photographed by the Department of Medical Illustration, University of New South Wales.

\section{References}

1 Jefferson G. Observations on trigeminal neuralgia. $\mathrm{Br}$ Med J 1931;2:879-83.

${ }^{2}$ Rowbotham GF. Observations on the effects of trigeminal denervation. Brain 1939;62:364-80.

${ }^{3}$ Oka M. Experimental study on the vasodilator innervation of the face. Med J Osaka Univ 1950;2:109-16.

${ }^{4}$ Sweet WH, Wepsic JG. Controlled thermocoagulation of trigeminal ganglion and rootlets for differential destruction of pain fibers. Part. 1: Trigeminal neuralgia. $J$ Neurosurg 1974;39:143-56.

${ }^{5}$ Onofrio BM. Radiofrequency percutaneous Gasserian ganglion lesions. Results in 140 patients with trigeminal pain. J Neurosurg 1975;42:132-9.

${ }^{6}$ Drummond PD, Lance JW. Extracranial vascular reactivity in migraine and tension headache. Cephalalgia 1981;1:149-55.

' Moskowitz MA, Reinhard JF Jr, Romero J, Melamed E, Pettibone DJ. Neurotransmitters and the fifth cranial nerve: is there a relation to the headache phase of migraine? Lancet 1979;2:883-5.

${ }^{8}$ Fox RH, Goldsmith R, Kidd DJ. Cutaneous vasomotor control in the human head, neck and upper chest. $J$ Physiol 1962;161:298-312.

9 Gonzalez G, Onofrio BM, Kerr FWL. Vasodilator system for the face. J Neurosurg 1975;42:696-703.

${ }^{10}$ Matthews B, Robinson PP. The course of postganglionic sympathetic fibres distributed with the trigeminal nerve in the cat. J Physiol (Lond) 1980;303:391-401.

${ }^{11}$ Barlow CM, Root WS. The ocular sympathetic path between the superior cervical ganglion and the orbit in the cat. J Comp Neurol 1949;91:195-207.

${ }^{12}$ Lewis T, Landis EM. Some physiological effects of sympathetic ganglionectomy in the human being and its effect in a case of Raynaud's malady. Heart 1930;15:151-76.

${ }^{13}$ Bill A, Stjernschantz J, Mandahl A, Brodin E, Nilsson G. Substance P: Release on trigeminal nerve stimulation, effects in the eye. Acta Physiol Scand 1980;106:371-3.

14 Brodin E, Gazelius B, Lundberg JM, Olgart L. Substance $P$ in trigeminal nerve endings: Occurrence and release. Acta Physiol Scand 1981;111:501-3.

15 Jancso N, Jancso-Gabor A, Szolcsanyi J. Direct evidence for neurogenic inflammation and its prevention by denervation and by pretreatment with capsaicin. $B r J$ Pharmac Chemother 1967;31:138-51.

${ }^{16}$ Parkinson D, Johnston J, Chaudhuri A. Sympathetic connections to the fifth and sixth cranial nerves. Anat $\operatorname{Rec}$ 1978;191:221-6.

${ }^{17}$ Gray's Anatomy (35th ed). Warwick R, Williams PL, eds. Norwich: Longman, 1973. 